\title{
AUTOMATED GEOMETRY CONTROL OF PRECAST SEGMENTAL BRIDGES
}

\author{
Kavin Kumar \\ Larsen \& Toubro, ECC Construction Group, \\ Chennai, India \\ Koshy Varghese \\ Department of Civil Engineering, I.I.T. Madras \\ koshy@iitm.ac.in
}

\author{
K. Senthil Nathan \\ Larsen \& Toubro, ECC Construction Group \\ Chennai, India \\ K. Ananthanarayanan \\ Department of Civil Engineering, I.I.T. Madras \\ kananth@iitm.ac.in
}

\begin{abstract}
The short-line match-cast joint method of pre-casting concrete segments has proved to be the most versatile and reliable way to building pre-cast segmental bridges. The essential feature of match casting is that successive segments are cast against adjoining segment in the correct relative orientation with each other starting from the first segment away from the pier. The segments are subsequently erected on the same order and hence no adjustments are required between segments during assembly.

The success of short-line match-cast joint method relies heavily on accurate geometry control during match casting as the scale of adjustments during erection is very small and difficult to implement. The required levels of accuracy in positioning the segments match-cast against each other are stringent in order to assure acceptable tolerances in the geometry of the structure.

It was found that even a fraction of millimeter of error in segment casting gets amplified to several meters at the end of the bridge span and can result in significant rework. Stringent control of geometry and successive correction of errors are required to ensure that the geometry of the bridge is maintained.

The paper will describe the match-casting process and the sources of errors in the process. Next the detailed steps to determine and correct the error are discussed. Finally a conceptual system comprising of a laser based measurement, processor controlled and a servo based form adjustment is proposed to automate the entire process.
\end{abstract}

\section{KEYWORDS}

Segmental Bridges, Match-casting, Short-line method, Geometry control

\section{INTRODUCTION}

Pre-cast construction of bridge members has several advantages in comparison with cast-in-place bridge construction. The key advantage is that casting of the segments can be performed under controlled, plant-like conditions at the pre-cast yard.

Figure 1 shows reinforcement for a typical pre-cast segment and Figure 2 shows the segment after completion. The industrialized process allows easy 
quality control of segments prior to placement in the superstructure and saves money through reuse of the pre-casting formwork. Further, surface finishing works, such as texturing, sandblasting, painting, and coating can be performed on the ground level without scaffolding when the segments are still accessible from all sides prior to installation in the superstructure.

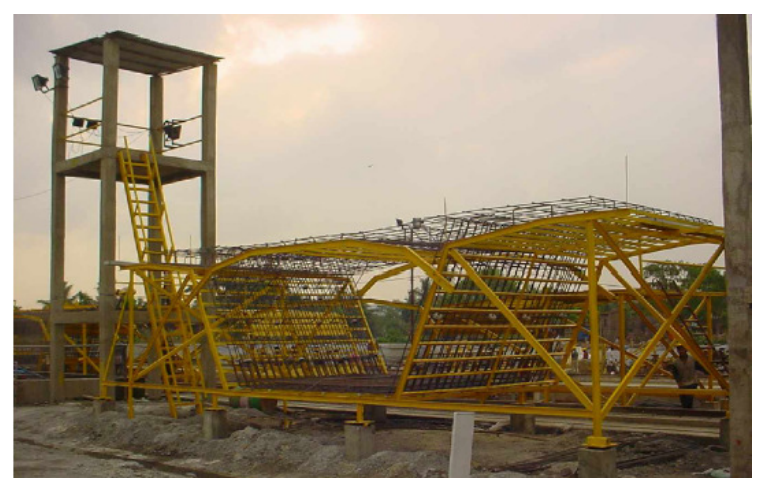

Figure 1. Reinforcement for Segment

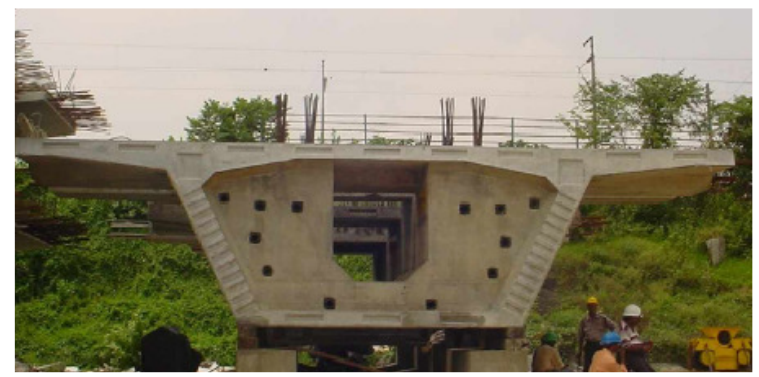

Figure 2. Typical Precast Segment

Another major advantage mentioned by Mathivat [1] is that the complete casting of the superstructure can be removed from the critical path of the overall construction schedule, since superstructure "segments can be precast during construction of the substructure." Assembly of the bridge superstructure takes much less time than cast-in-place construction, as precast segments have gained more strength and do not need to cure on site before being pre-stressed together [2].

Match-casting is an important concept in the construction of precast segmental construction. This was developed by Jean Muller [3] and it allows the transverse slicing of concrete box girders and the assembly of such slices - the segments - in the same order as they were produced, without any need for additional in situ concrete to complete the bridge deck. Match-casting using the short-line method is illustrated in Figure 3. This is done by ensuring that the segments are cast in the formwork between a "bulkhead at one end and an already cast segment at the other" [4]. The segments are cast in the casting yard one at a time. The segments are cast against the previous one so that the end face of one segment will be an imprint of the neighbor segment, ensuring a perfect fit at the erection.

One of the key elements to effective match-casting is accurate geometry control. Control of geometry is important as the tolerances are in the order of a fraction of a millimeter and any deviation in excess of this will result in misalignment of the bridge. The error becomes more critical when there are horizontal and vertical curves in the bridge alignment. On a recent project it was found that the accurate calculation and correction of the errors in the matchcasting process was tedious and caused delays in the casting process. While software for the geometry control is commercially available [2], its use is restricted to specialty consultants and expensive. The objective of this paper is to present the basic issues in the geometry control issue and present an broad steps for error calculation. Using this algorithm the errors and corrections required can be calculated rapidly and will not be a bottleneck for the match-casting process.

A description of the match-casting process is given in the next section. The third section presents the steps for error analysis. The fourth section presents the approach to implement the algorithm and further automate the match-casting process.

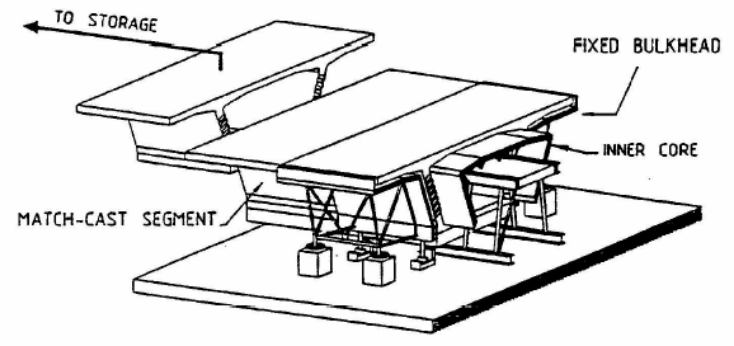

Figure 3. Match Casting Using Short-Line Method [2] 


\section{SHORT-LINE METHOD}

Short-line match casting method can be adopted for building a deck with any geometry. The geometry of the bridge is solely controlled during the casting of the segments. It offers very little option to control the geometry of the bridge or the span during the erection process. The principles behind the match casting operation to obtain the above mentioned geometry are discussed in the following text.

\subsection{Match Casting for a Straight Bridge}

When a straight bridge is desired, the match marking mate segment ( $\mathrm{n}-1)$ is moved from the casting position to the match-cast position along a straight line, and this usually verified by taking measurements on the punched plates embedded on the concrete during casting. A pure translation of each segment between the cast and match-cast positions therefore results in the construction of a perfectly straight bridge (both in elevation and plan view), within the accuracy of the measurements made at the site.

\subsection{Match-casting for a vertical curve}

To obtain a bridge with a vertical curve, the matchcast segment (n-1) must first be translated from its original position and then give a small rotation in the vertical plane with respect to the horizontal axis as shown in Figure 4. Usually the bulkhead is left in the fixed position, and all segments have in elevation projected shape of a
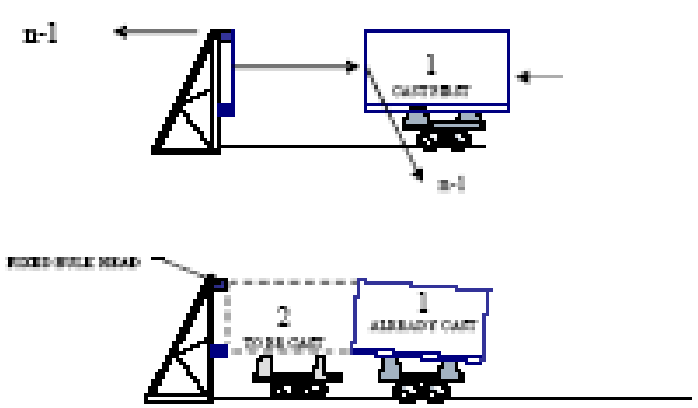

Figure 4. Adjustment for Vertical Curve [4]

rectangular trapezoid with the tapered face along the match-cast segment. It is therefore only necessary to adjust the soffit of the cast segment during the adjustment operations.

\subsection{Match-casting for a horizontal curve}

To obtain a bridge with horizontal curve the matchcast segment $(n-1)$ is first moved to its position by pure translation and then the segment is rotated in plan with respect to the vertical axis as shown in figure 5. The adjustment is done at the soffit level. The new cast segment takes the trapezoidal shape in the plan due to the rotation of the match-cast segment.

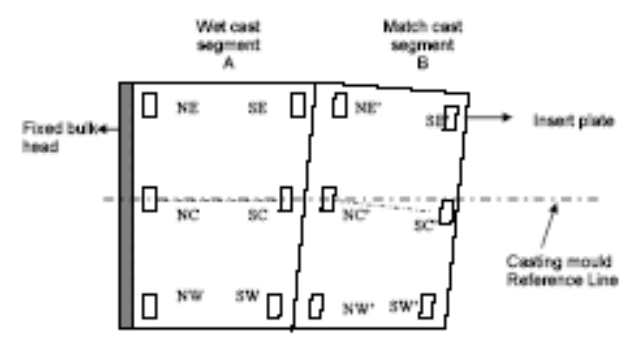

Figure 5. Adjustment for Horizontal Curve

\subsection{Geometry Control Procedure}

Before starting the construction on site it is required to established a system of stations at North and South side of mould. For setting out, the polar method is used [5]. The coordinates (match casting $\&$ conjugate segment coordinates) of the design points (6 points of each segment) are pre-calculated and recorded in the memory of the Total Station. Setting out works is done from the closest station (survey tower). The orientation is observed from minimum two stations, to avoid mistakes and to check the actual accuracy of the instrument.

\subsubsection{Survey}

The marking of both axis lines is done before starting of any activity on each mould. The surveyor fixes the bulkhead position (fixed and temporary) with the Total Station and confirms that the position and level of bulkhead are accurate. The surveyor also checked the soffit level as per pre-calculated level and accordingly if necessary soffit levels was adjusted. After checking the bulkhead and soffit, the surveyor marks the four corners coordinates of segments. Six insert plates are at $50 \mathrm{~mm}$ from edge 
and $9.0 \mathrm{~m}$ from centre of segment for punching coordinates after casting. The level of the insert plate is fixed as per theoretical level from a Survey Tower.

After casting of segments, the surveyor directs the crew to punch the coordinates on the 6 insert plates as per theoretical casting coordinates. The levels of the 6 insert plates are checked. Elevation and centerline offset measurements are adjusted to an accuracy of $\pm .0 .3 \mathrm{~mm}$.

After punching of coordinates that segment is placed in conjugate (n-1) segment position and in that position that segment is fixed as per theoretical match-cast coordinates. The levels of the segment are checked at insert plate locations as per theoretical level and accordingly if necessary the levels are adjusted using the bottom jack adjustment system. At the time of positioning of the segment the surveyor indicates the theoretical position of insert plates (which was already punched). Once the theoretical position reaches $(\mathrm{X}, \mathrm{Y})$, the segment is fixed in that position. The coordinates and levels at all insert plates locations are finally checked after fixing the conjugate segment (n-1). After completion of formwork and reinforcement the set up position of two adjacent segments are independently determined by two observers and difference between two observation should not be more than: for Elevation $\pm 0.6 \mathrm{~mm}$ on control points and For Horizontal: $\pm 0.6 \mathrm{~mm}$ on a segment centreline offset.

\subsubsection{Correction for Geometric Deviation}

During casting of the segments there are possibilities of deviation of the segment geometry from the theoretical geometry. The deviation arises due to wrong alignment of the match-cast segment or due to some thermal stresses. If the deviation in the geometry is not accounted then there will be a serious error in the alignment of the whole bridge geometry. In order to avoid any significant deviation from the theoretical geometry, it is necessary to provide for corrections when casting the next segment. Similar corrections are done for the vertical alignment. It is essential to check the superelevation (given by the crosswise difference in level of the insert plates) varies regularly according to the theoretical geometry. Failure to do so will result in misalignment.

The goal of the geometry control program will be to monitor the casting operations and establish "ascast" curves step-by-step to verify that the actual superstructure geometry is in close agreement with the theoretical casting curves. After each segment is cast, the position of this segment is established in the general plot of the structure. Comparing the location of the newly cast segment with the location assumed in the casting curve will allow for the determination of the adjustments required before the next pour.

\section{GEOMETRY CONTROL PROGRAM}

The overall logic of the geometry control program requires the following steps:

1. Calculate the theoretical casting coordinates of segment $\mathrm{n}$.

2. Measure the actual casting coordinates

3. Calculate error in casting

4. Calculate correction to be made in casting $\mathrm{n}+1$ match-casting with $\mathrm{n}$

5. Adjust match-casting of $\mathrm{n}$ to compensate for error while casting $n+1$

Additional details of the steps and the equations for calculating the errors are presented in the appendix and discussed by Kumar [6].

\section{AUTOMATED GEOMETRY CONTROL}

With the current level of automation technologies, the entire match-casting process can be automated through the use of laser measurement, automated error computation and servo controlled form adjustment.

A schematic of the proposed process is shown in Figure 6. In this scheme, the locations of the punch plates are constantly monitored through a laser based system and fed to a processor. The processor computes the deviation in real time and uses a servo based form control to adjust for the error. Feedback is sent to the processor by the servo as well as the laser measurement system. 


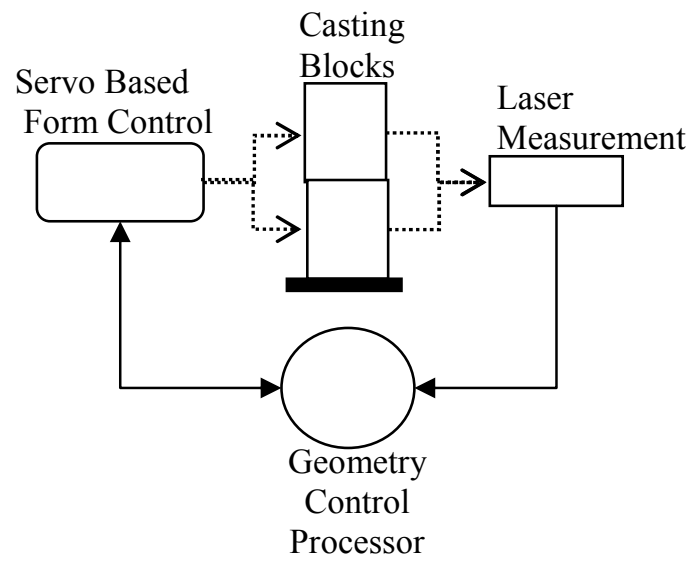

Figure 6. Schematic for Automated Geometry Control

\section{SUMMARY}

This paper has presented the basic steps involved in the match-casting process for the construction of segmental bridges and illustrated the sources of errors and the process of correcting the errors. The tolerance for error is so small that extremely accurate calculations and form settings are critical to maintain the final geometry of the bridge.

The proposed automated geometry control method promises to reduce the tediousness of the current method and speed-up the casting process considerably. Today, where minimizing the duration of a project is of utmost importance, such schemes have high potential of implementation.

\section{REFERENCES}

[1] Mathivat, J. (1983). "The Cantilever Construction of Prestressed Concrete Bridges”. A Wiley-Interscience Publication, John Wiley \& Sons, Inc, New York, NY.

[2] http://www.ids-soft.com/solutions/ products/geometrey.html visited March 28, 2008.

[3] Podolny, W., Muller, J. M. (1982)." Construction and Design of Prestressed Concrete Segmental Bridges." A Wiley-Inter-science Publication, John Wiley \& Sons, Inc., NewYork, NY.

[4] Levintov, B. (1995), "Construction Equipment for Concrete Box Girder Bridges." Concrete International 17(2), P 43-47.

[5] Prabhakaran, P.K, Senthilnathan, K., and Balaji, S. (2002). "Short line matchcasting and erection of precast segments for DMRL", The Indian Concrete Journal, 721 - 724 .

[6] Kavin Kumar,(2006) "Geometry Control During Casting Of Precast Segmental Bridges By Short-Line Method" M.Tech Thesis, I.I.T. Madras, May 2006

\section{APPENDIX A}

\section{Step 1}

Calculation of distances from the cell reference point to the joints of the wet cast segment and match cast segment (Fig. A.1).

Distance $=$
Sqrt $\left[(\mathrm{x} 2-\mathrm{x} 1)^{\wedge} 2+(\mathrm{y} 2-\mathrm{y} 1)^{\wedge} 2+(\mathrm{z} 2-\mathrm{z} 1)^{\wedge} 2\right]-------(1)$

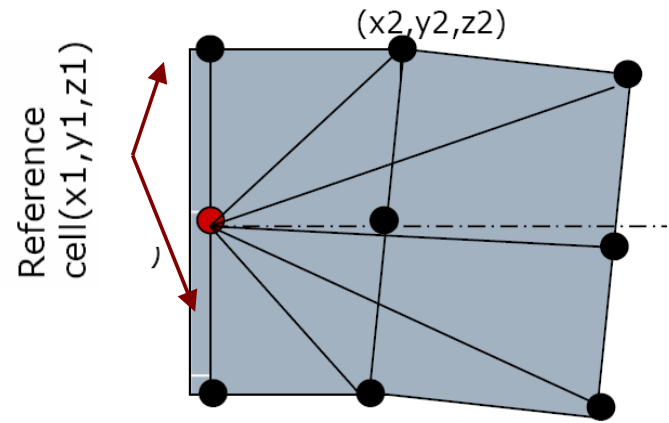

Figure A.1 Calculation of Distance Between two Coordinates

\section{Step 2}

Calculation of X-offset and Y-offset of the joint coordinates with respect to the reference cell (Fig. A.2).

\section{Step 3}

Calculation of X-offset and Y-offset at the insert plate location. Typically the insert plates are fixed at $50 \mathrm{~mm}$ distance from the edge (Fig. A.3). 


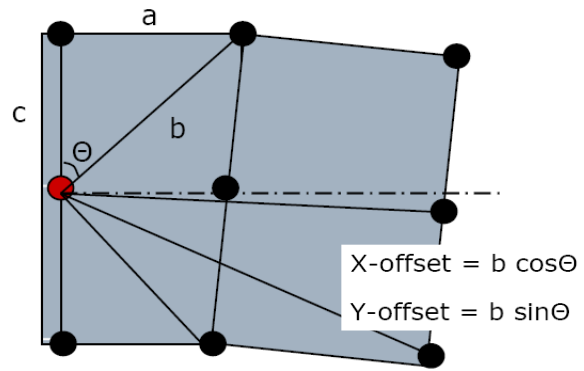

Figure A.2 Calculation of X-offset and Y-offset Distances

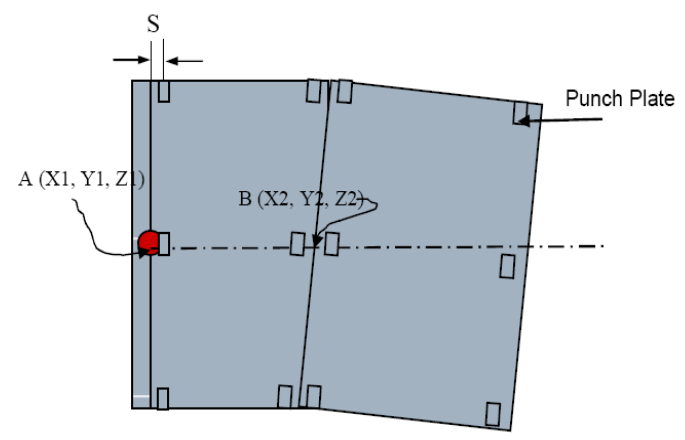

Figure A.3 Calculation of Casting Coordinates at Insert Point Locations

Let the offset distance $=\mathrm{S}(50 \mathrm{~mm}$ followed at site $)$

Let the corner coordinates of two points $\mathrm{A}$ and $\mathrm{B}$ be $(\mathrm{X} 1, \mathrm{Y} 1, \mathrm{Z} 1)$ and $(\mathrm{X} 2, \mathrm{Y} 2, \mathrm{Z} 2)$

Let Distance between $\mathrm{A}$ and $\mathrm{B}=\mathrm{D}$

Let Xsb, Ysb, Zsb be the Coordinates at S distance inside point A (bulkhead face), then

$\mathrm{Xsb}=\mathrm{X} 2-((\mathrm{X} 2-\mathrm{X} 1) \times \mathrm{S}) / \mathrm{D})$

$\mathrm{Ysb}=\mathrm{Y} 2-((\mathrm{Y} 2-\mathrm{Y} 1) \times \mathrm{S}) / \mathrm{D})$

$\mathrm{Zsb}=\mathrm{Z} 2-((\mathrm{Z} 2-\mathrm{Z} 1) \times \mathrm{S}) / \mathrm{D})$

Let Xsm, Ysm, Zsm be the coordinates at $\mathrm{S}$ distance inside point $\mathrm{B}$ (match face).Then,

$\mathrm{Xsm}=\mathrm{X} 1+((\mathrm{X} 2-\mathrm{X} 1) \times \mathrm{S}) / \mathrm{D})$

$\mathrm{Ysm}=\mathrm{Y} 1+((\mathrm{Y} 2-\mathrm{Y} 1) \times \mathrm{S}) / \mathrm{D})$

$\mathrm{Zsm}=\mathrm{Z} 1+((\mathrm{Z} 2-\mathrm{Z} 1) \times \mathrm{S}) / \mathrm{D})$

\section{Step 4}

Calculation of vertical level difference between the reference cell and punch coordinates (Fig. A.4, A.5).

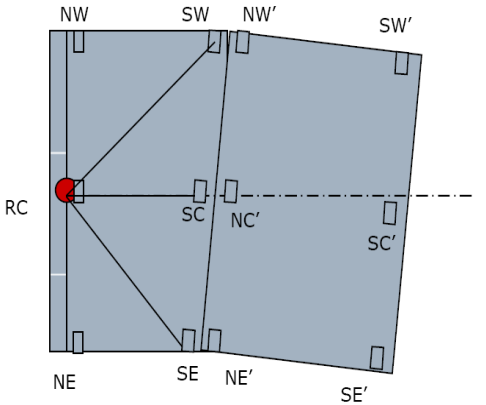

Figure A.4 Vertical Levels

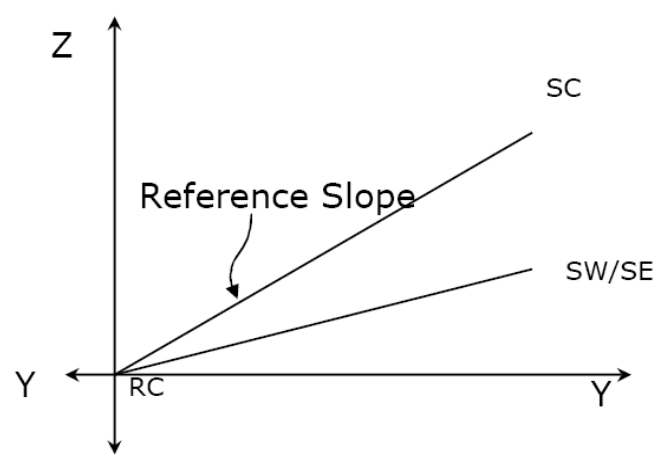

Figure A.5 Reference for Insert Plate Levels

Slope of Reference Plane (RC-SC) = (Z COORD of RC $-\mathrm{Z}$ COORD of SW) / (Y-OFFSET OF RC-SC)

Slope of RC-SW =

(Z COORD of RC - Z COORD of SW) / (YOFFSET OF RC-SW)) ----------------- (9)

Level diff. of SW with respect to $\mathrm{RC}=$ (Difference. in slope of RC-SC and RC-SW) X (Yoffset of RC-SW) (10)

\section{Step 5}

Correction for horizontal alignment:

Theoretical X-offset of NC'

w.r.t to reference cell $=\mathrm{NXt}$

As-cast X-offset NC'

w.r.t to reference cell $=\mathrm{NXa}$

Theoretical X-offset SC' 
w.r.t to reference cell $=\mathrm{SXt}$

As-cast X-offset SC'

w.r.t to reference cell $=\mathrm{SXa}$

Correction to be applied in the NC punch plate of the wet cast segment

$=-(\mathrm{NXt}-\mathrm{NXa})$

Correction to be applied in the SC punch plate of the wet cast segment

$=-($ SXt- SXa $)$

\section{Step 6}

Correction for vertical alignment (Fig. A.6):
Theor. diff. slope of RC-NW' = NLWt

Theor. diff.1 slope of RC-NE' = NLEt

Theor. diff.1 slope of RC-SW' = SLWt

Theor. diff. slope of RC-SE' = SLEt

Actual diff. slope of RC-NW' $=$ NLWa

Actual diff. slope of RC-NW' $=$ NLEa

Actual diff. slope of RC-NW' $=$ SLWa

Actual diff. slope of RC-NW' $=$ SLEa

Correction for the wet cast segment:

NLWc $=-[(N L W t-N L W a) X$ Y-offset $]$ (13)

NLEc $=-[(N L W t-N L E a) X$ Y-offset $]$--- (14)

SLWc $=-\left[(N L W t-S L W a)^{*} Y\right.$-offset $]$---- (15)

SLEc $=-[(N L W t-S L E a) * Y-o f f s e t]-$

\section{FLOW-CHART}

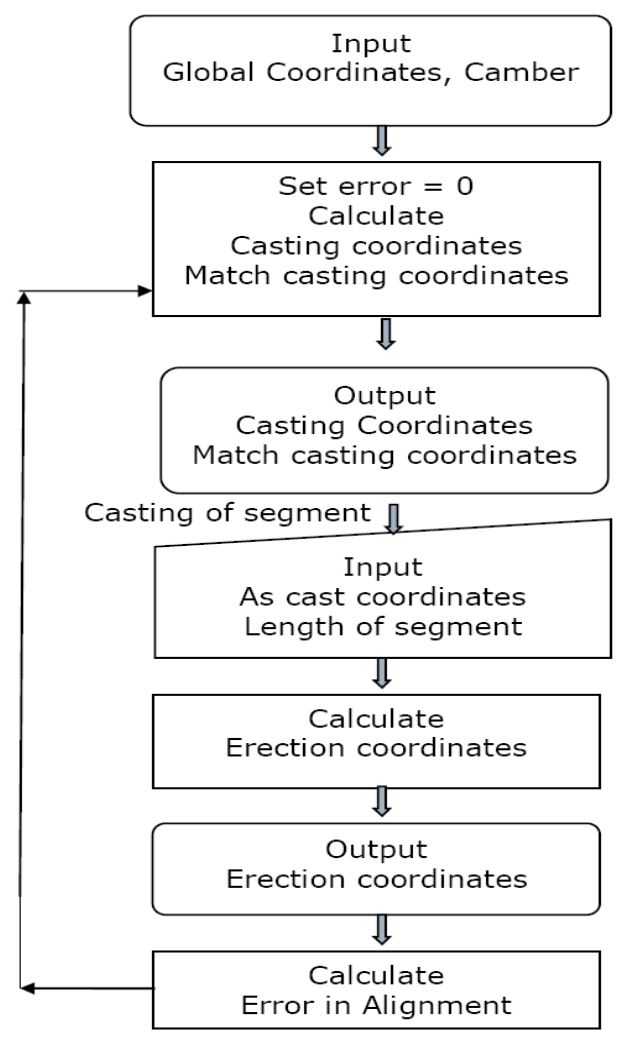

Figure A.6 Program Flow Chart 